\title{
ROMPgel-supported Thiazolium lodide: An Efficient Supported Organic Catalyst For Parallel Stetter Reactions
}

Anthony G. M. Barrett, ${ }^{*}$ Andrew C. Love and Livio Tedeschi

Department of Chemistry, Imperial College London, Exhibition Road, London SW7 2AZ, England agmb@imperial.ac.uk

Supporting Information 2 of 2

2. Additional Spectra Continued 


\section{Additional Spectra Continued}

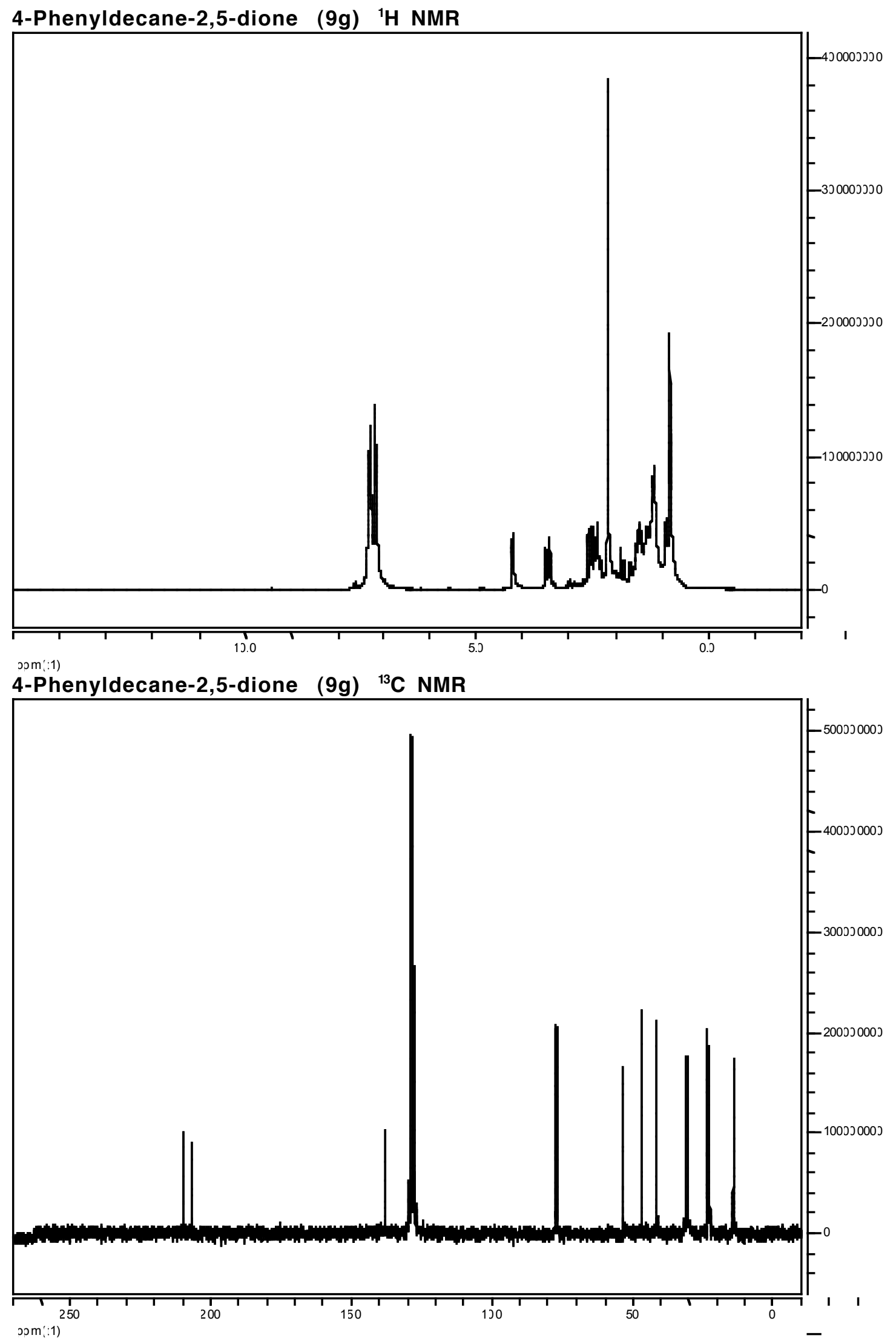




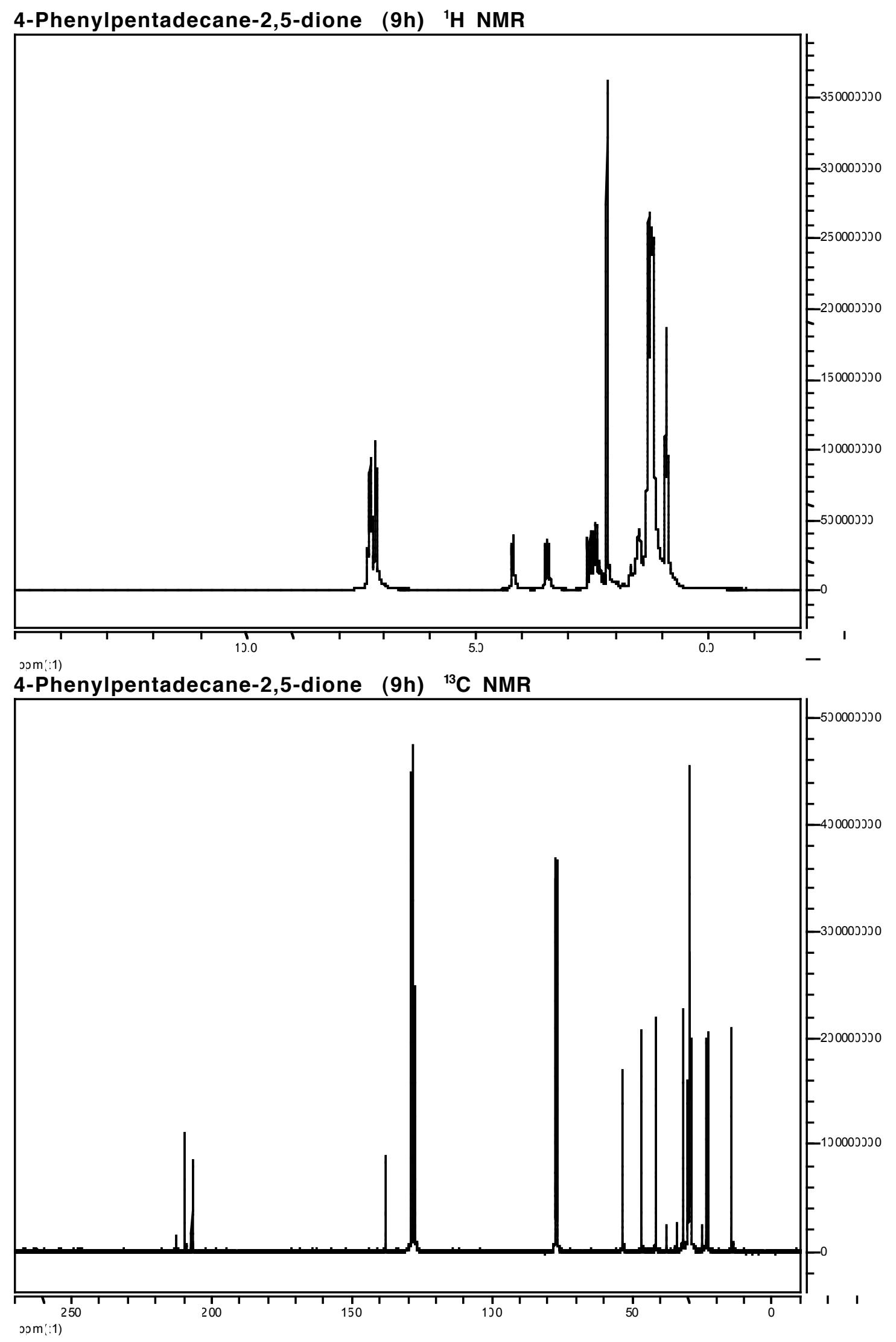




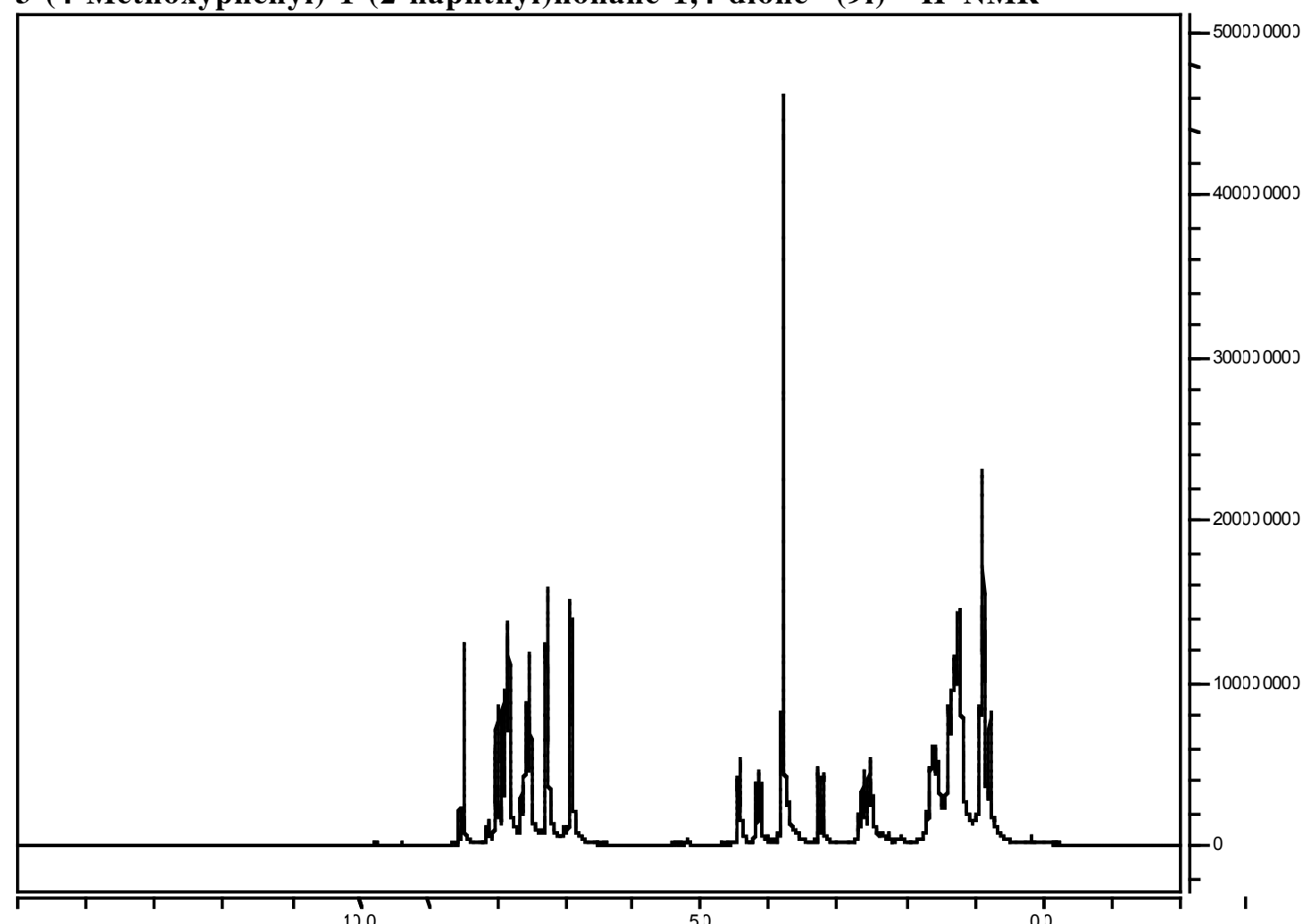

วрm::1)

3-(4-Methoxyphenyl)-1-(2-naphthyl)nonane-1,4-dione (9i) ${ }^{13} \mathrm{C}$ NMR

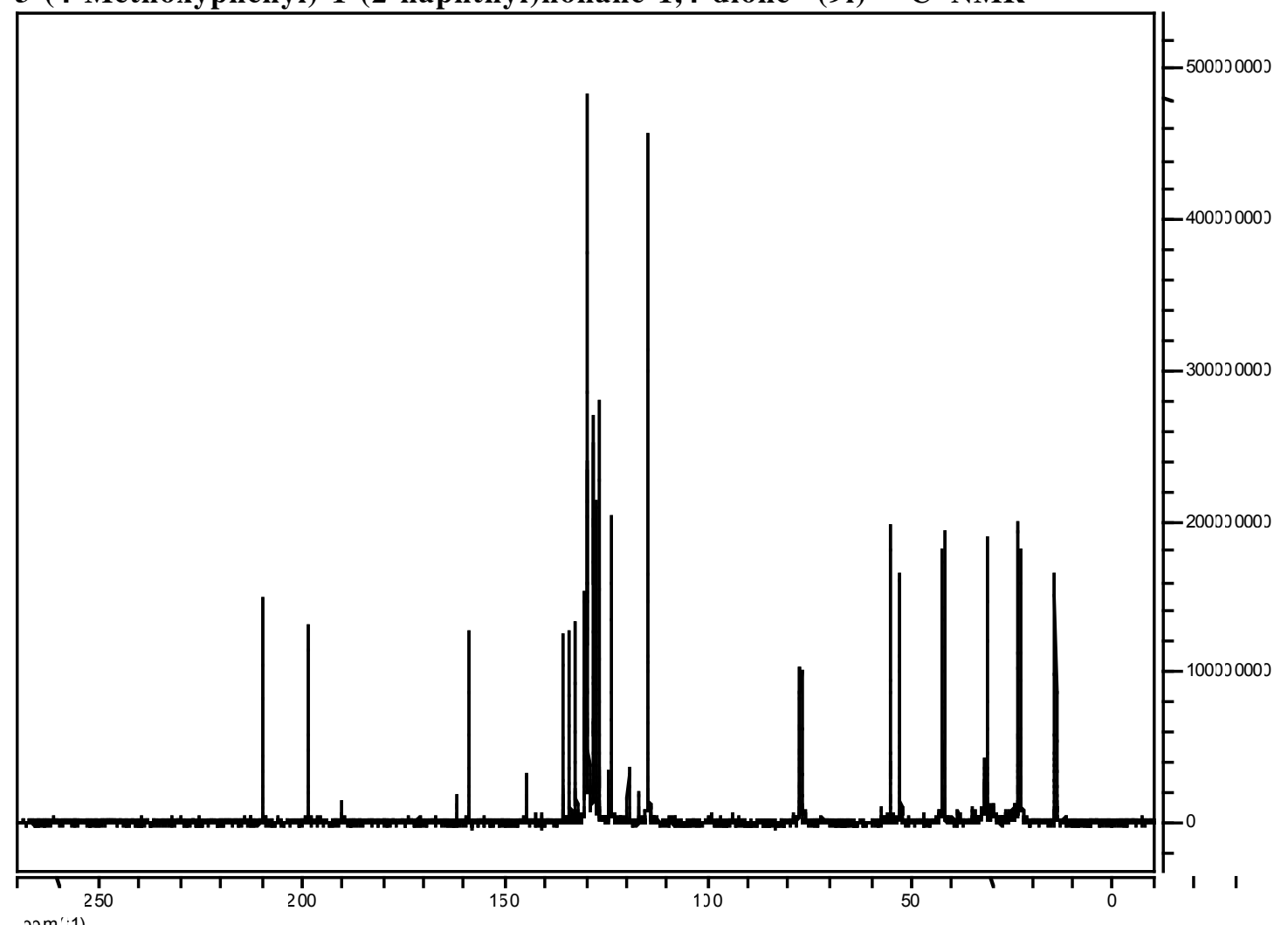

วот':1) 


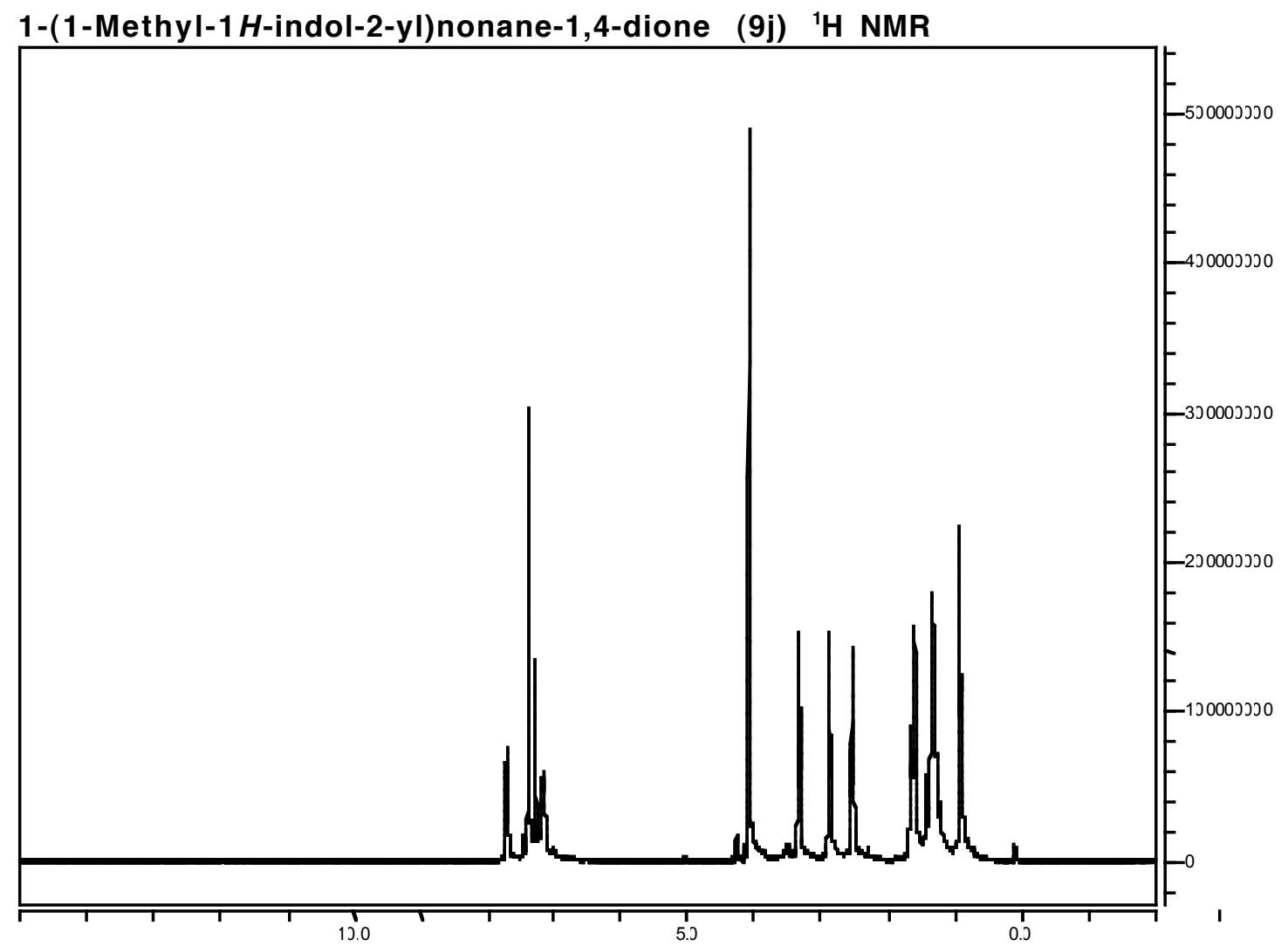

эрт;:1)

1-(1-Methyl-1H-indol-2-yl)nonane-1,4-dione $(9 \mathrm{j}){ }^{13} \mathrm{C}$ NMR

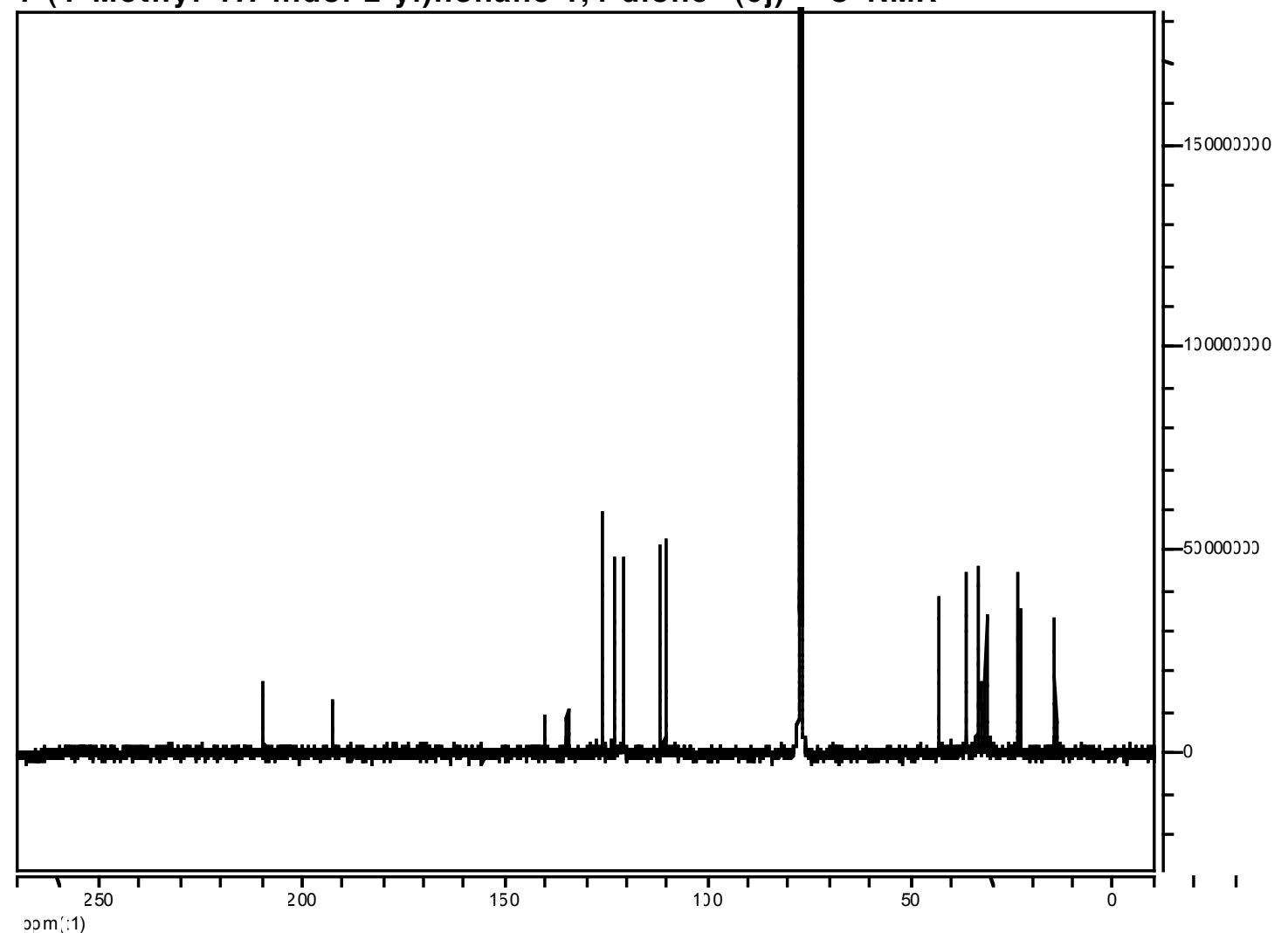

วо $\left.m^{\prime}: 1\right)$ 


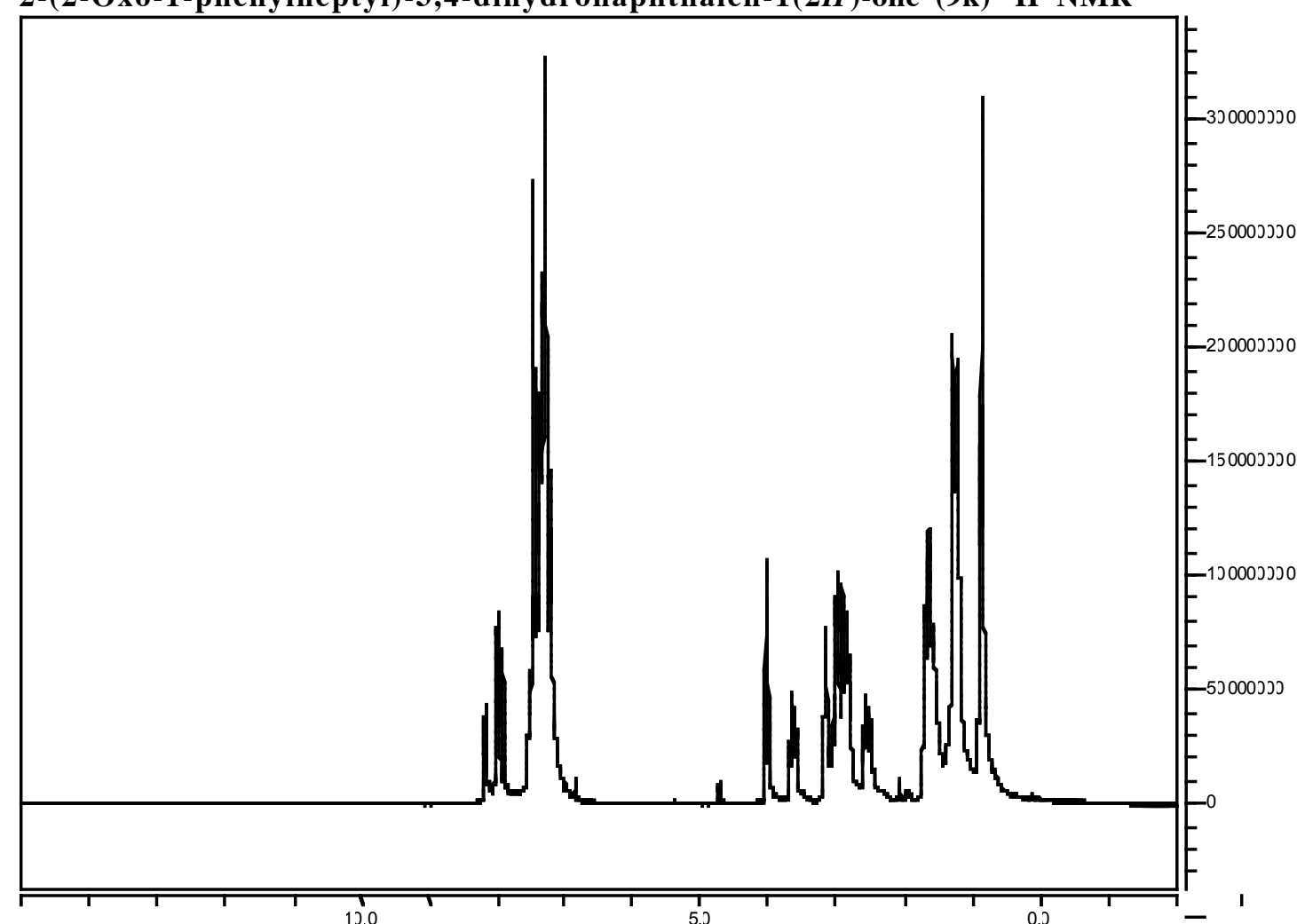

эрт::1)

2-(2-Oxo-1-phenylheptyl)-3,4-dihydronaphthalen-1(2H)-one (9k) ${ }^{13} \mathrm{C}$ NMR

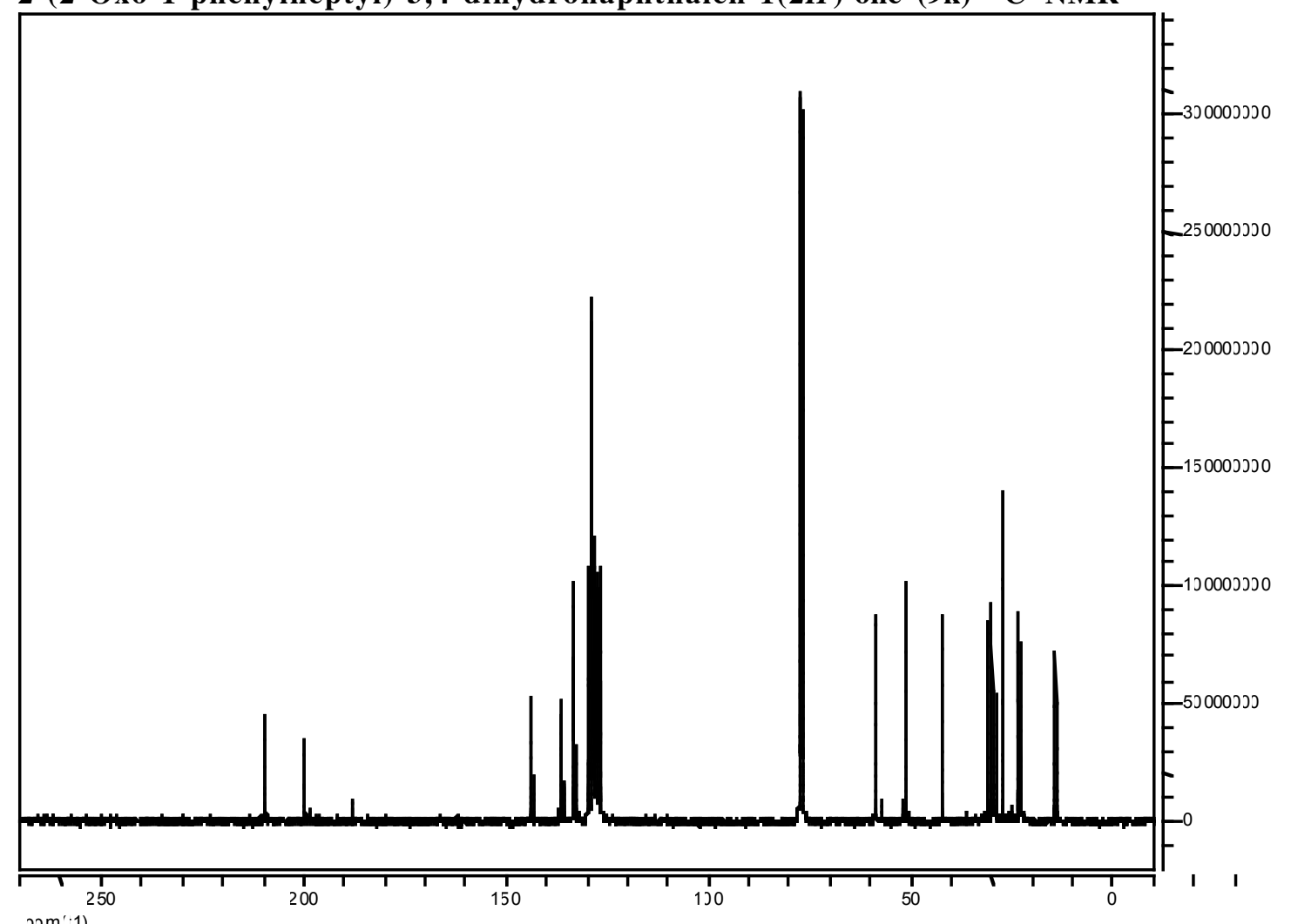

วоm::1) 


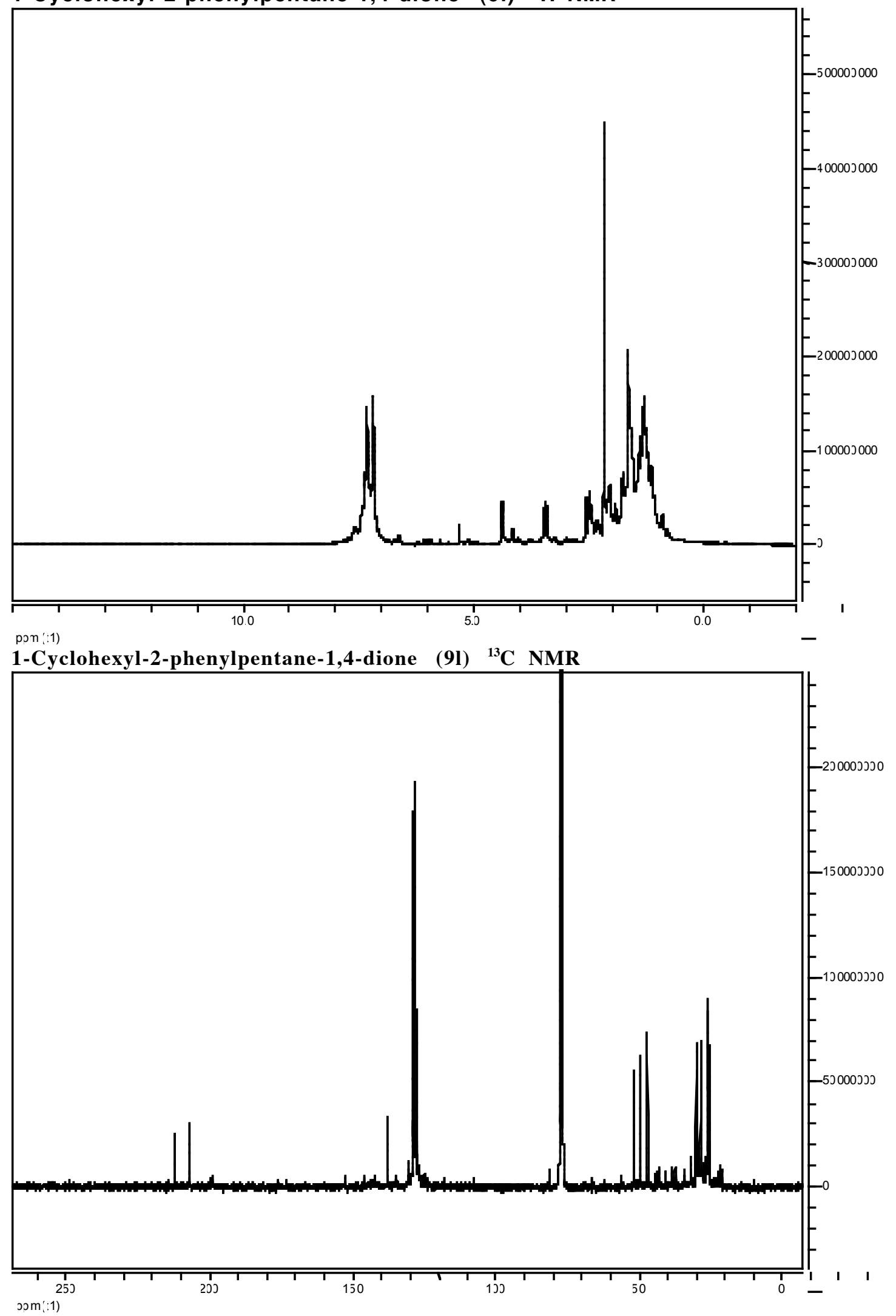




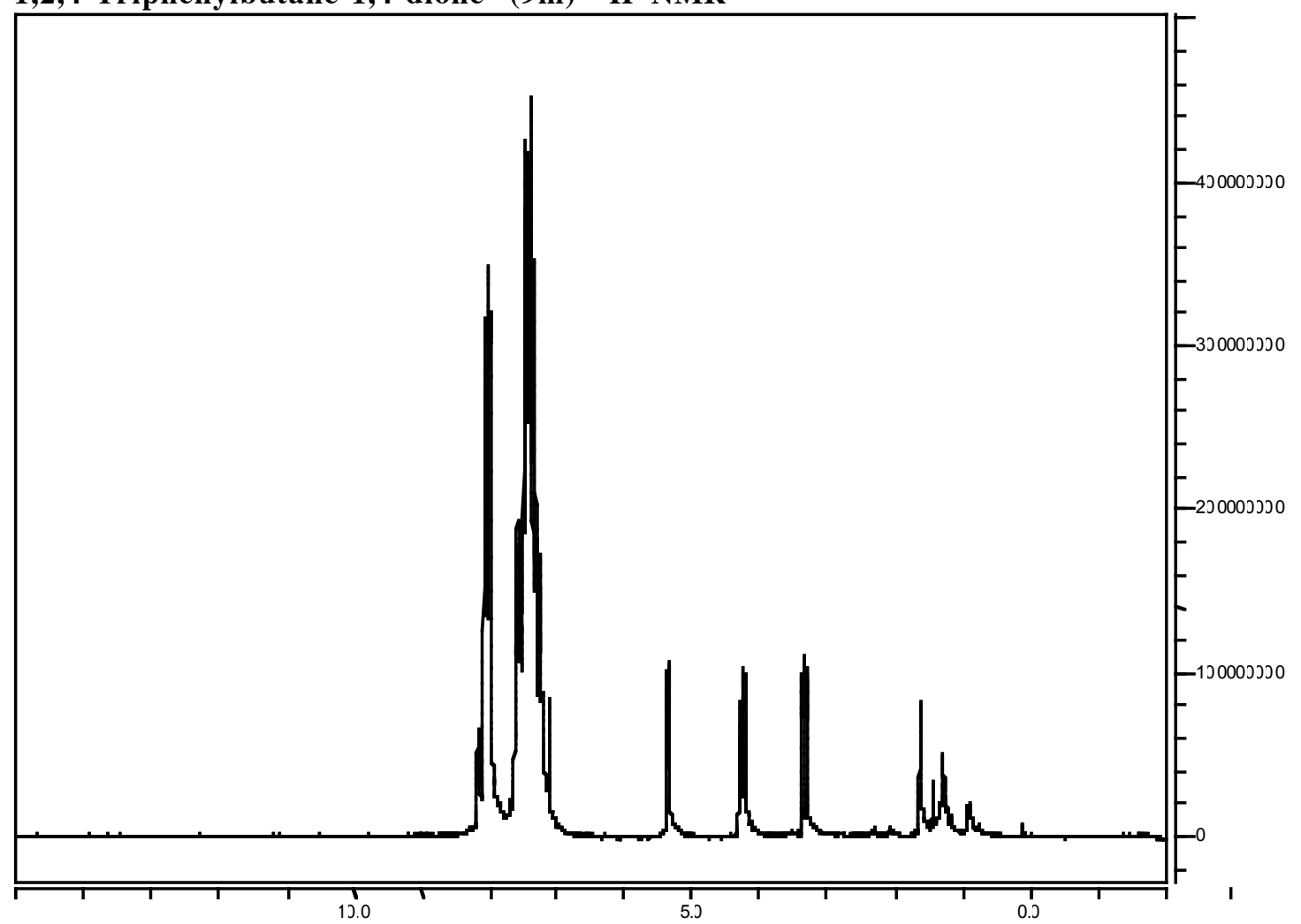

วот : :1)

1,2,4-Triphenylbutane-1,4-dione $(9 \mathrm{~m}){ }^{13} \mathrm{C}$ NMR

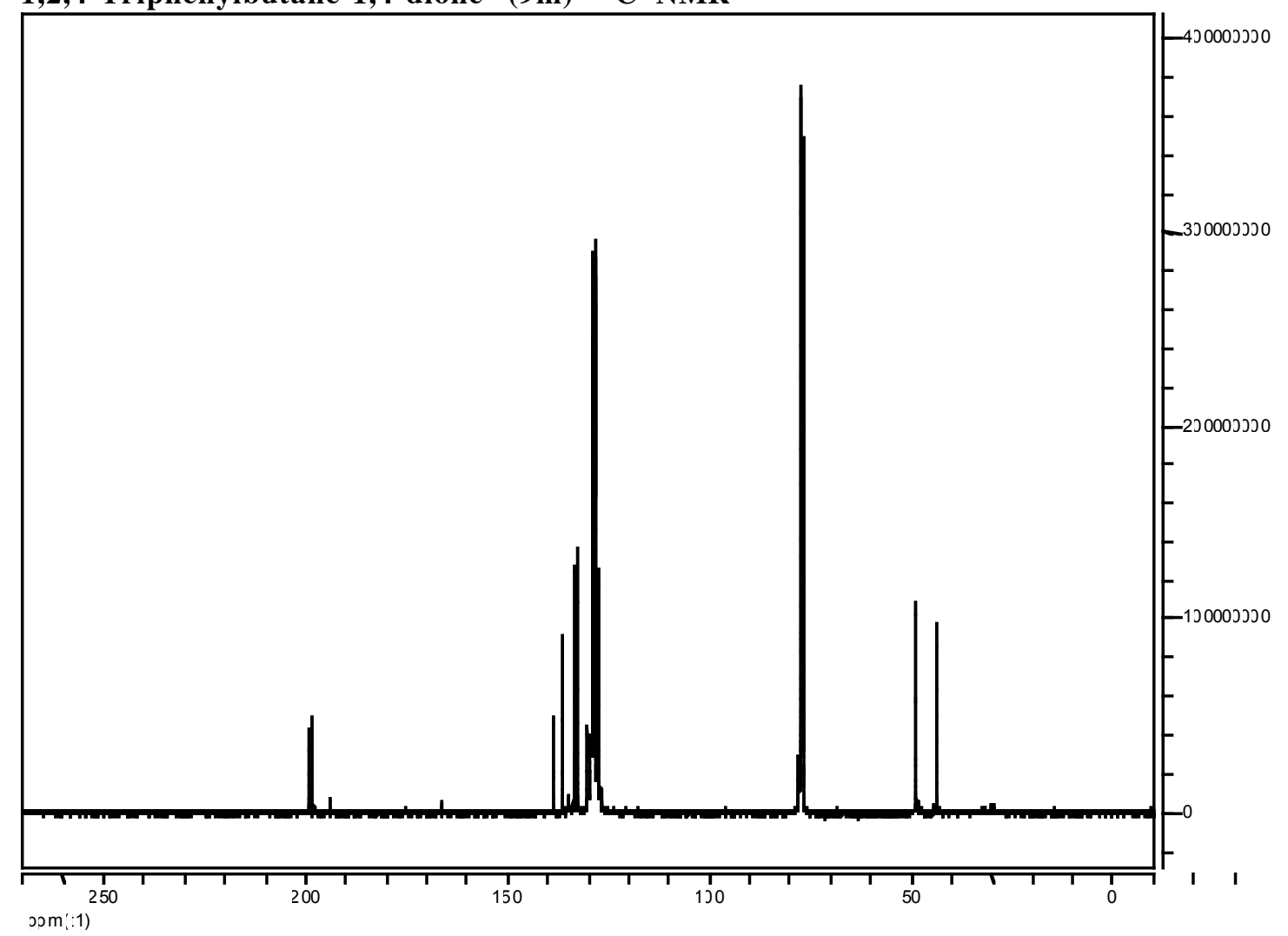

эрт (:1) 


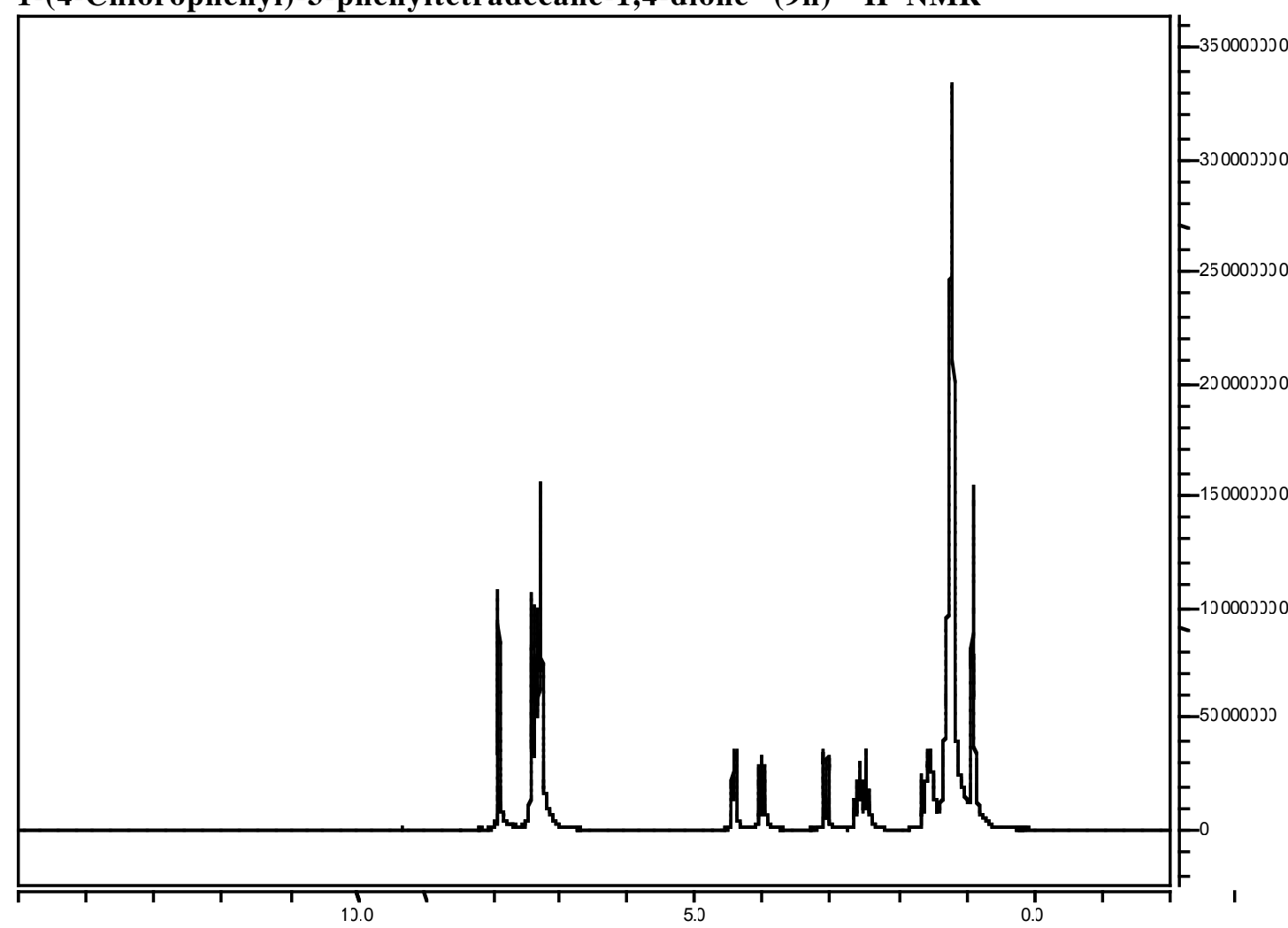

วот':1)

1-(4-Chlorophenyl)-3-phenyltetradecane-1,4-dione (9n) ${ }^{13} \mathrm{C}$ NMR

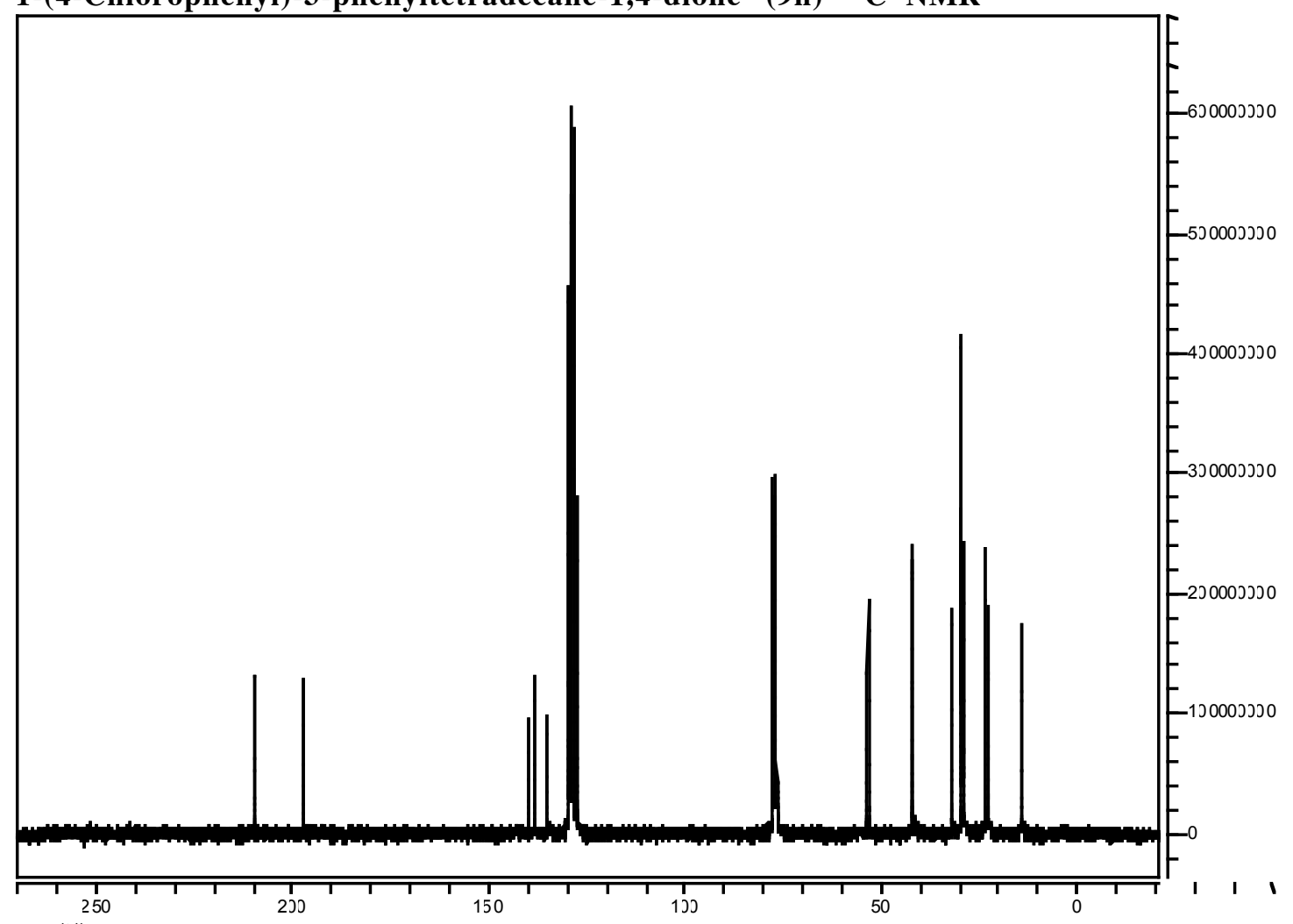

วоm':1) 


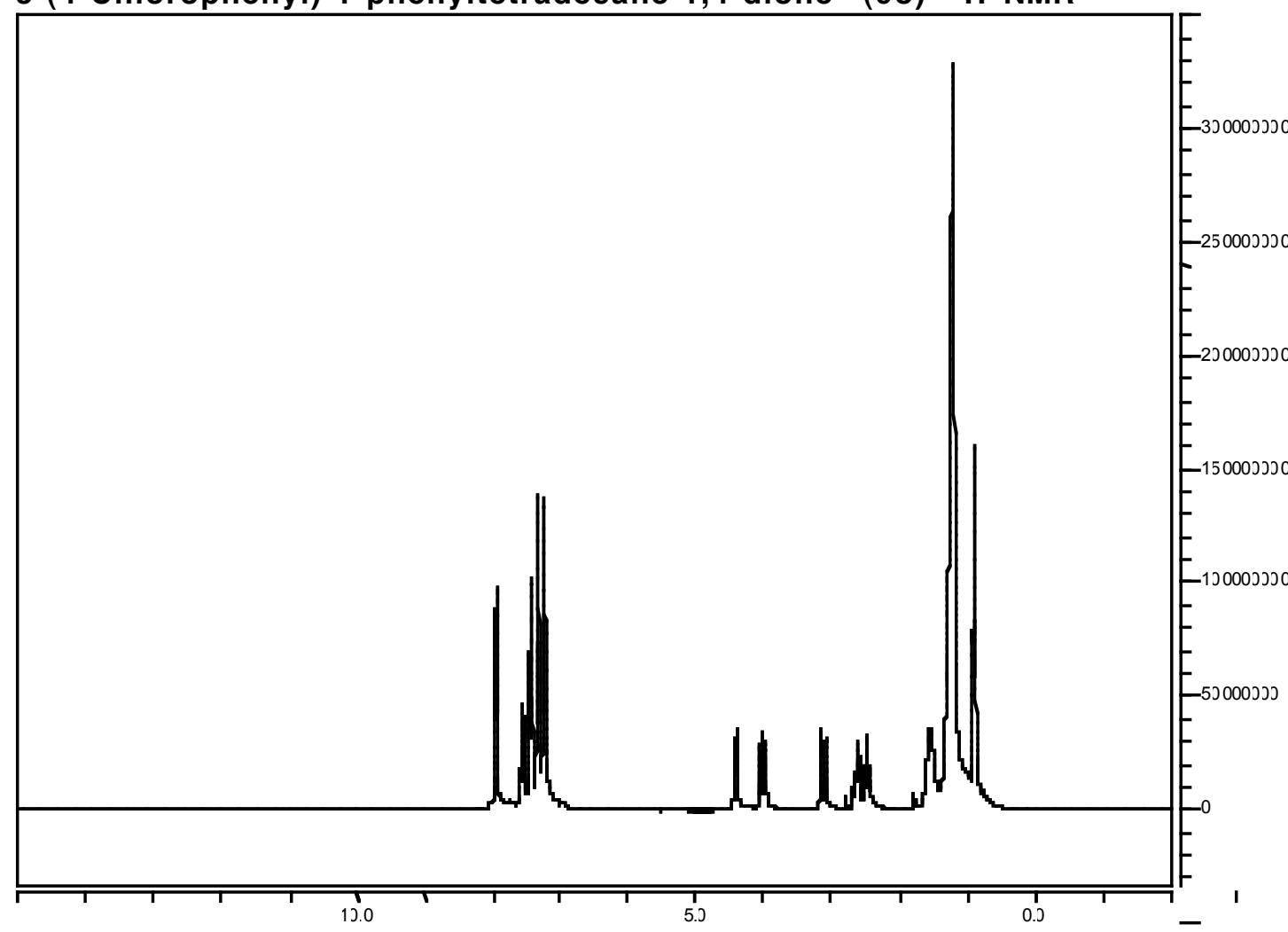

эрт':1)

3-(4-Chlorophenyl)-1-phenyltetradecane-1,4-dione (9o) ${ }^{13} \mathrm{C}$ NMR

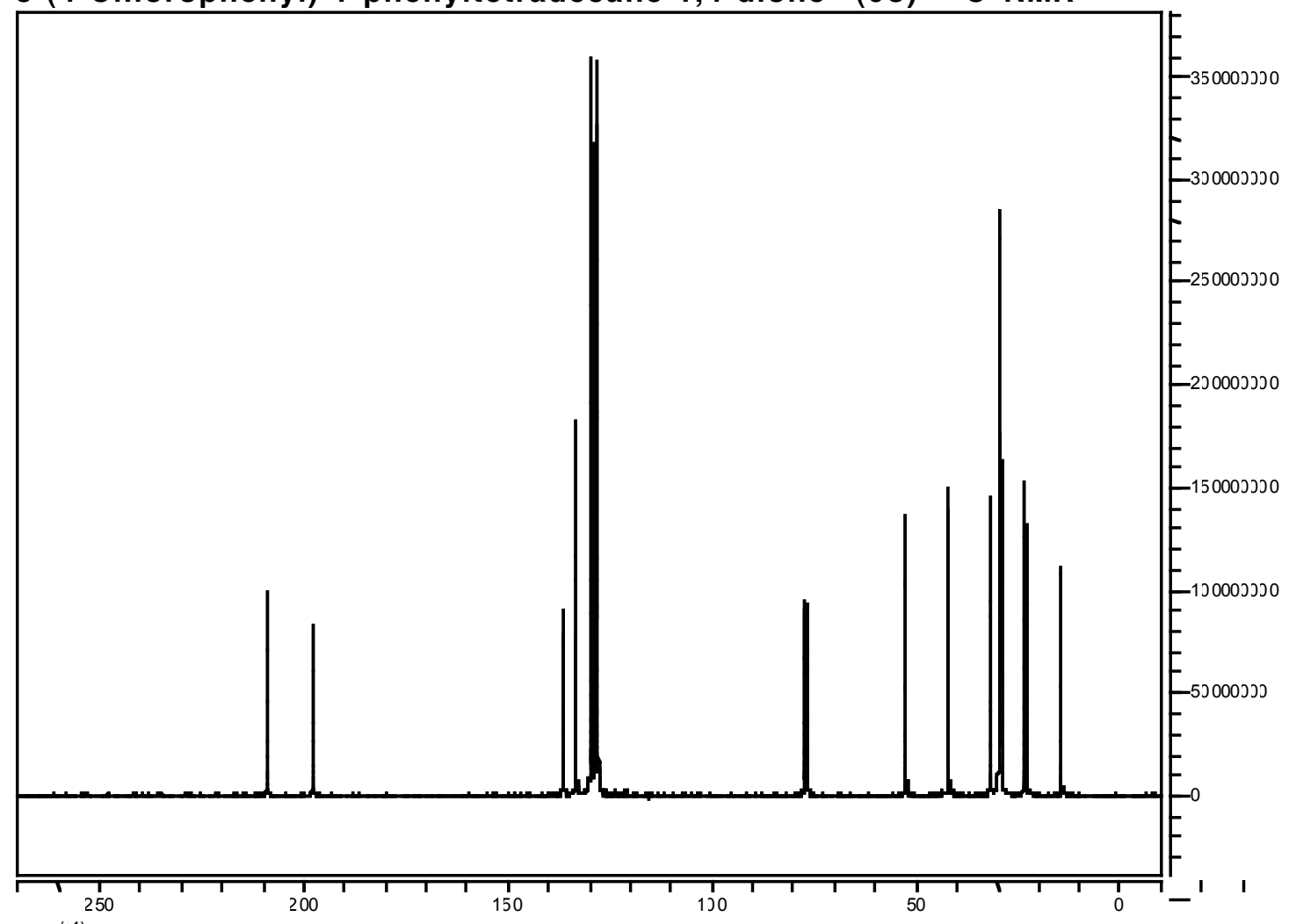

วpm::1) 


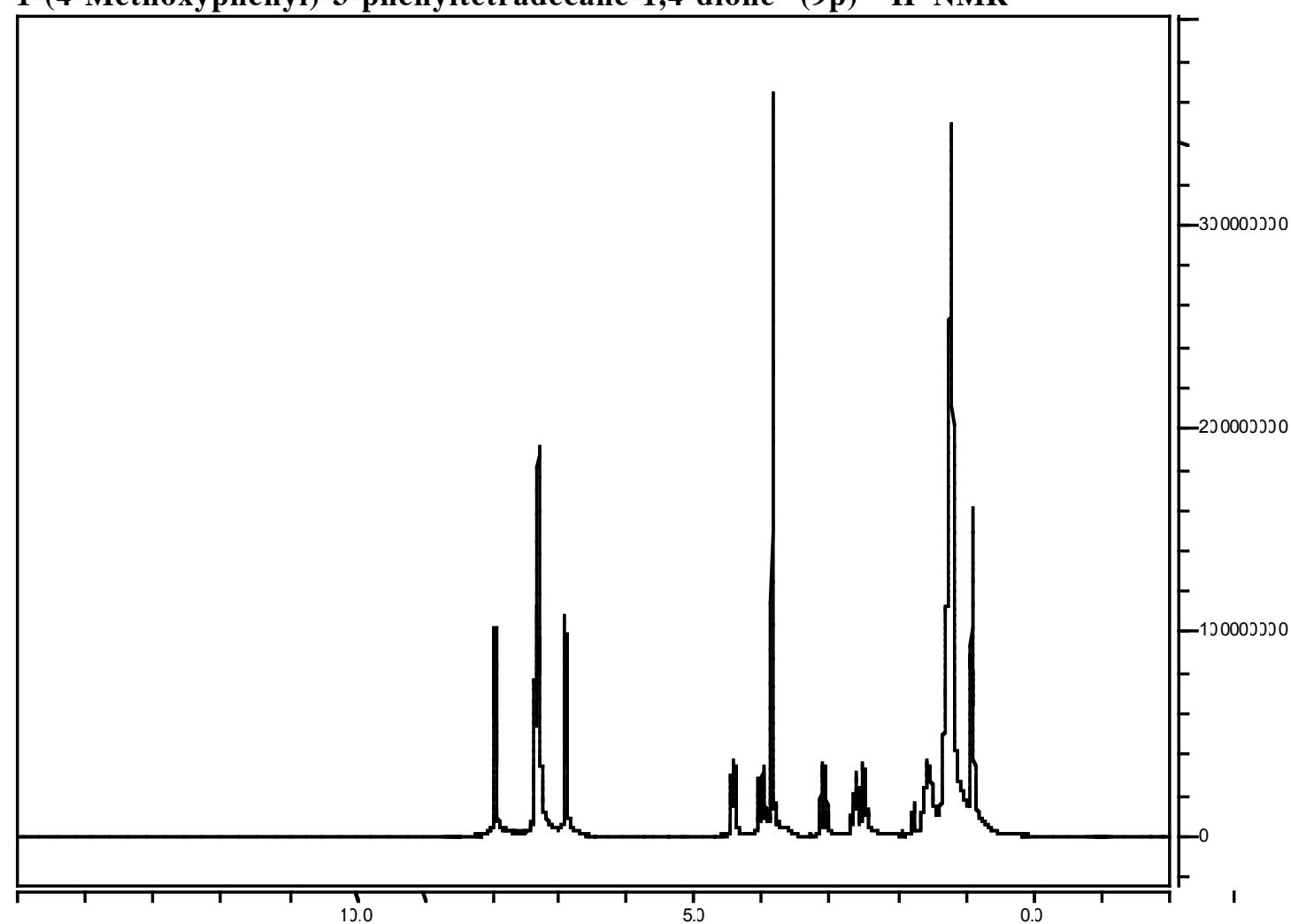

วот':1)

1-(4-Methoxyphenyl)-3-phenyltetradecane-1,4-dione (9p) ${ }^{13} \mathrm{C}$ NMR

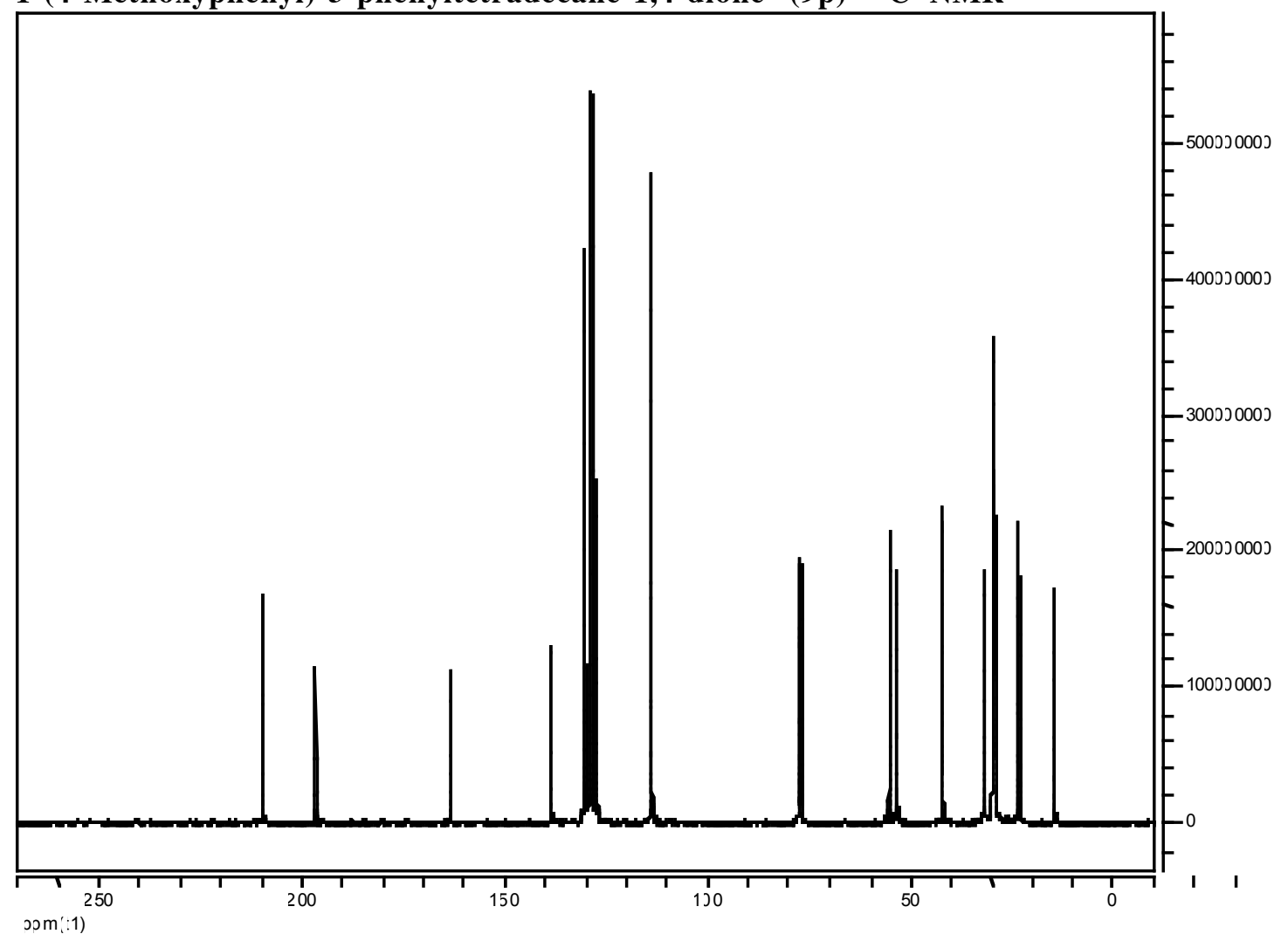

วо $\left.m^{\prime}: 1\right)$ 


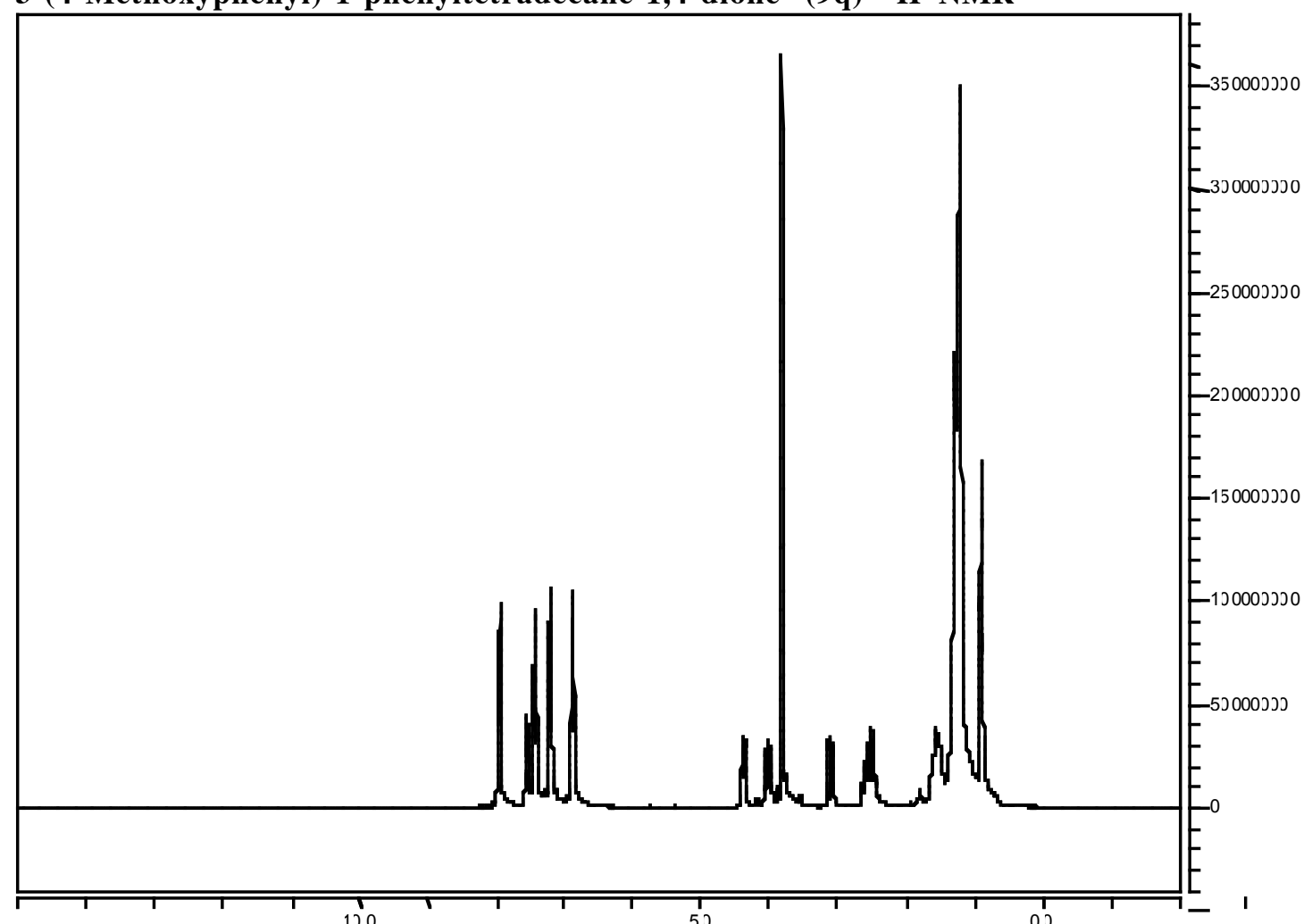

эрт ::1)

3-(4-Methoxyphenyl)-1-phenyltetradecane-1,4-dione (9q) ${ }^{13} \mathrm{C}$ NMR

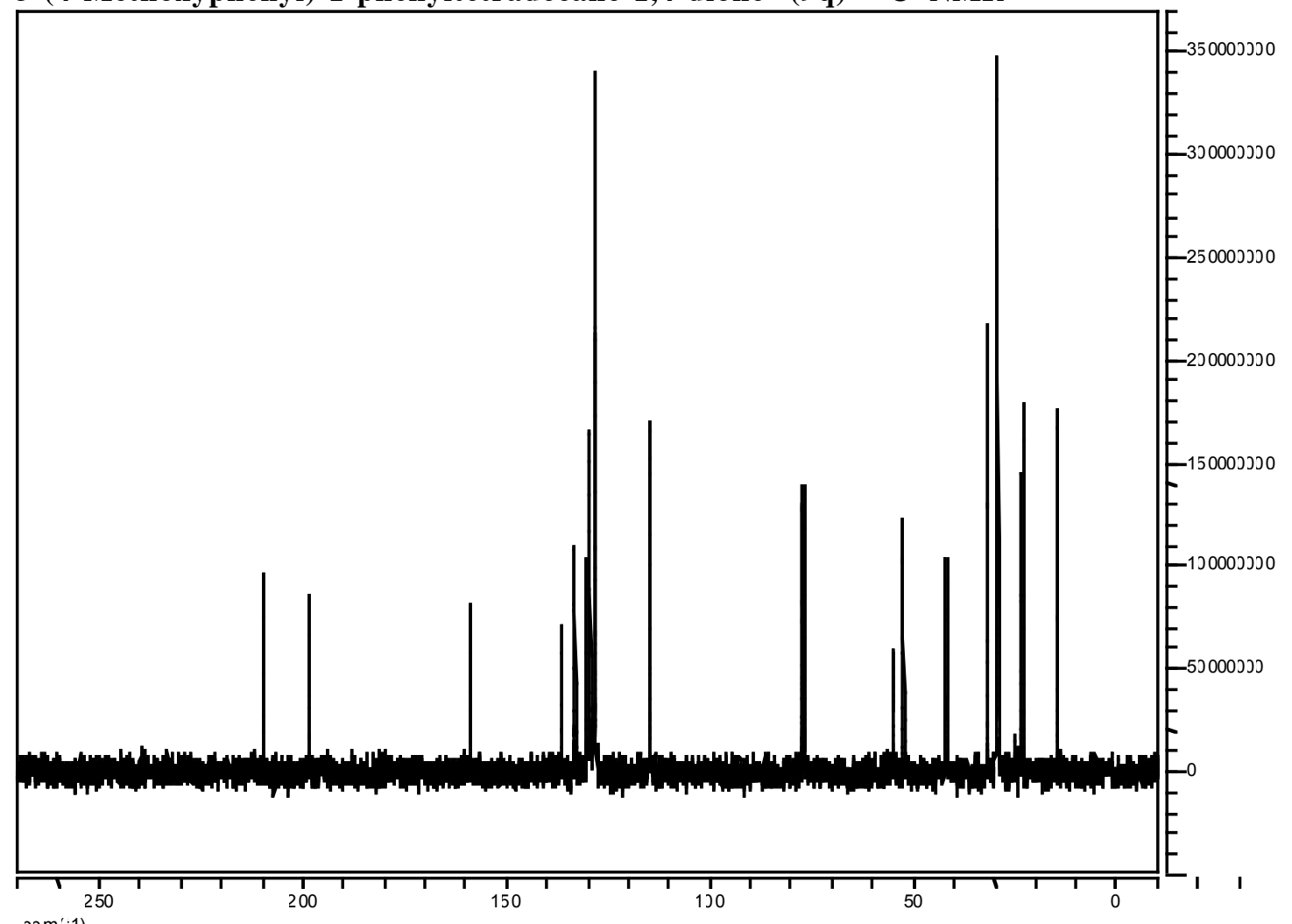

วоm::1) 